\title{
Metabolism and regulation of canonical histone mRNAs: life without a $\operatorname{poly}(\mathrm{A})$ tail
}

\author{
William F. Marzluff, Eric J. Wagner, and Robert J. Duronio \\ Program in Molecular Biology and Biotechnology, University of North Carolina at Chapel Hill, Chapel \\ Hill, North Carolina 27599, USA.
}

\begin{abstract}
The canonical histone proteins are encoded by replication-dependent genes and must rapidly reach high levels of expression during $\mathrm{S}$ phase. In metazoans the genes that encode these proteins produce mRNAs that, instead of being polyadenylated, contain a unique 3' end structure. By contrast, the synthesis of the variant, replication-independent histones, which are encoded by polyadenylated mRNAs, persists outside of S phase. Accurate positioning of both histone types in chromatin is essential for proper transcriptional regulation, the demarcation of heterochromatic boundaries and the epigenetic inheritance of gene expression patterns. Recent results suggest that the coordinated synthesis of replication-dependent and variant histone mRNAs is achieved by signals that affect formation of the $3^{\prime}$ end of the replication-dependent histone mRNAs.
\end{abstract}

Histones are the primary protein component of chromatin. Although they were initially thought to be mainly involved in chromosomal DNA packaging in eukaryotes, it is now recognized that they also have a crucial role in regulating gene expression. Histones can be extensively modified after translation and these modifications play an important part in regulating gene expression. They are constantly being shifted, modified, evicted and re-deposited as chromatin is continually remodelled (reviewed in REF. ${ }^{1}$ ). Thus, the cell must carefully coordinate the replication of DNA, the synthesis of an estimated $10^{8}$ molecules of each histone type in mammalian cells and the rapid deposition of new and old histones to reform chromatin during each relatively short $\mathrm{S}$ phase $\mathrm{e}^{2,3}$.

In metazoans the bulk of the histone proteins, defined here as the canonical histone proteins, are encoded by a family of replication-dependent histone genes. Their mRNAs are the only known cellular non-polyadenylated mRNAs in eukaryotes ${ }^{4}$. These genes encode all four core histones - H2A, H2B, H3 and $\mathrm{H} 4$ - which make up the nucleosome, and the linker $\mathrm{H} 1$ histones, which are found between nucleosomes. In place of a poly(A) tail, replicationdependent histone mRNAs end in a $3^{\prime}$ stem-loop sequence that is crucial in their regulation (FIG. 1a), and is formed by endonu-cleolytic cleavage of the pre-mRNA (FIG. 1b). This novel $3^{\prime}$ end results in the requirement for a distinct set of factors for metabolism and regulation of these histone mRNAs. These mRNAs must be expressed rapidly at the beginning of S phase and must persist at high levels throughout $S$ phase to coincide with the replication of DNA. They are destroyed at the conclusion of S phase or rapidly during S phase if DNA replication is halted.

In addition to the canonical histones, there are several variant histones whose synthesis is not cell-cycle-regulated and whose mRNAs are polyadenylated and expressed throughout the cell cycle (replication-independent histone mRNAs). These histones include the H3.3 and 
H2A.Z proteins (H2Av in Drosophila melanogaster), CENPA (histone H3-like centromeric protein A, present at centromeres), macro-H2A and histone H1.0. The major variants of the core histones are H3.3 and H2A.Z, which are found in all multicellular organisms. These proteins mark active genes and are thought to contribute to defining chromatin boundaries.

In this Review we discuss results from recent years that have substantially advanced our understanding of the metabolism and regulation of the canonical histone mRNAs and that have provided the first clues into how the metabolism of the canonical histone mRNAs and variant histones are coordinated. We also highlight the emergence of some surprising recent findings about the evolutionary origin of histone genes.

\section{Replication-dependent histone mRNAs}

Like polyadenylated mRNAs, metazoan canonical histone mRNAs have a 7-methyl-guanosine cap at the $5^{\prime}$ end. However, unlike polyadenylated mRNAs, histone mRNAs end in a stemloop, which consists of a 6 base stem and 4 nucleotide loop. Altogether, the $3^{\prime}$ end of canonical histone mRNAs consists of a conserved 25-26 nucleotide sequence that includes the 5 nucleotides before the stem-loop, the 16 nucleotide stem-loop and the 4-5 nucleotides after the stem-loop (FIG. 1c). The stem-loop sequence is evolutionarily conserved in metazoans with a number of elements that are invariant (FIG. 1c), including sequences in the stem, in the loop and before the stem-loop. A single protein, the stem-loop binding protein (SLBP), binds to this 26 nucleotide sequence and participates in all aspects of histone mRNA metabolism. SLBP has a small, 73 amino acid RNA-binding domain (RBD) that is not similar to the RBD of any other RNA-binding protein 5,6 .

In most species, histone $\mathrm{H} 1$ mRNAs have the same $3^{\prime}$ end as the other canonical histone mRNAs. Interestingly, however, in some organisms (for example, the nematodes Caenorhabditis elegans and Caenorhabditis briggsae) only the core histone genes end in a stem-loop, whereas the histone $\mathrm{H} 1$ genes encode polyadenylated mRNAs ${ }^{7}$. As the metabolism of histone $\mathrm{H} 1$ differs from that of the core histones and histone $\mathrm{H} 1$ turns over more rapidly. The absence of the stem-loop from histone H1 mRNA in these species does not affect the ability to coordinately express the four nucleosomal core proteins.

\section{Organization of canonical histone genes}

The high demand for canonical histone proteins during $\mathrm{S}$ phase is met by the coordinated expression of multiple copies of the histone genes in all metazoans. In mammals there are approximately 75 distinct canonical histone $\mathrm{mRNAs}^{8}$. The genes that encode these transcripts are clustered together in the genomes of all eukaryotic species studied so far, and these clusters typically contain multiple copies of the genes that encode the five distinct histone proteins. Thus, the canonical histone genes have remained tightly linked throughout metazoan evolution. Two types of clusters are commonly found: tandemly repeated gene sets, with the repeat unit containing one copy of each of the five histone genes; and 'jumbled' clusters, in which there is no common gene order and the individual genes for each histone protein are not identical. Within vertebrates, frogs have tandemly repeated clusters, whereas mammals and birds have jumbled clusters.

A dramatic example of tandemly repeated canonical histone genes occurs in $D$. melanogaster. There are about 100 copies of a $\sim 5 \mathrm{~kb}$ histone gene set, significantly more canonical histone genes than found in mammals, which have 20 -fold larger genomes. Thus, D. melanogaster seems to have many more canonical histone genes than are required for somatic cell cycles, with their relatively long $\mathrm{S}$ phases. However, this extensive duplication might be required at the end of oogenesis to provide sufficient canonical histone proteins for early embryonic development (see below). Alternatively, each individual gene might be 
expressed at a relatively low level. In either case, the tandem repeat organization ensures that an equal number of each histone mRNA is produced, providing a likely explanation for why this type of genomic organization has been maintained. The jumbled clusters found in mammals and birds might have been maintained to allow the definition of a nuclear subdomain in which efficient biosynthesis of histone mRNA can take place (see below).

Outside the canonical histone gene clusters in mammals there are only two canonical histone genes encoding non-polyadenylated mRNAs. One of these encodes the histone variant H2A.X, which is involved in recognition of DNA damage in chromatin ${ }^{9}$. The $3^{\prime}$ end of H2A.X mRNA expressed during $S$ phase is not polyadenylated, but in G0 and G1 phase transcription proceeds further and the mRNA ends in a poly(A) tail ${ }^{10}$. It is possible that the separation of the H2A.X gene from the major cluster plays a part in allowing the expression of both polyadenylated and non-polyadenylated mRNAs from the same gene. As the H2A.X protein is synthesized throughout the cell cycle ${ }^{11}$, the ability to make two different mRNAs ensures that an H2A.X mRNA is constitutively expressed. In addition, a single human histone $\mathrm{H} 4$ gene that is located outside any histone gene cluster expresses a non-polyadenylated mRNA in S phase $^{8}$. The function of this gene is not known; however, there is a syntenic copy in the mouse, suggesting that it has been conserved in mammalian evolution.

\section{Expression of canonical histone genes}

A consequence of having a unique $3^{\prime}$ end is that a different set of factors is required for the expression and function of histone mRNAs, including the U7 small nuclear RNA (snRNA) and the Sm-like proteins LSm10, LSm11, SLBP and SlBP-interacting protein 1 (SLIP1) (TABLE 1). Surprisingly, some factors involved in histone mRNA metabolism are not unique to the regulation of these mRNAs, but overlap with the poly(A) ${ }^{+}$mRNA metabolic machinery. Below we describe the steps in histone mRNA expression, focusing on data from experiments in mammalian and D. melanogaster cells. An overview of histone mRNA metabolism in mammalian cells is presented in FIG. 2.

\section{Transcription of canonical histone genes}

Mammalian genes encoding canonical histones are constitutively transcribed by RNA polymerase II and their rate of transcription increases as cells approach $S$ phase ${ }^{12}$. The nuclear protein ataxia-telangiectasia locus (NPAT) is present constitutively throughout the cell-cycle in Cajal bodies adjacent to histone genes (FIG. 3). NPAT is essential for entry into S phase ${ }^{13}$ and has a domain that stimulates histone gene transcription ${ }^{14,15}$. However, deletion of this domain does not prevent entry into $S$ phase, suggesting that NPAT might have multiple roles in histone mRNA biosynthesis ${ }^{13}$. At the beginning of S phase cyclin E-CDK2 (cyclindependent kinase 2) phosphorylates NPAT in these bodies ${ }^{14,16}$, and the phosphorylated form persists throughout $\mathrm{S}$ phase, resulting in increased expression of canonical histone genes.

\section{Formation of the 3' end of histone mRNA}

The genes encoding metazoan canonical histones lack introns, and thus an endonucleoytic cleavage that releases the nascent pre-mRNA from the DNA template is the only processing event necessary to form mature histone mRNA. In fact, insertion of an intron into a histone gene interferes with histone $3^{\prime}$ end formation, resulting in formation of polyadenylated histone mRNA $^{17}$.

There are many similarities between the endonucleoytic cleavage reaction that forms polyadenylated mRNAs and the reaction that forms histone mRNAs. For polyadenylated premRNAs, cleavage occurs between two cis elements: the hexanucleotide sequence consensus AAUAAA and a Gu-rich element located about 40 nucleotides downstream in poly(A) 
mRNAs ${ }^{18}$. For histone pre-mRNAs, cleavage occurs between the stem-loop and the histone downstream element (HDE), a purine-rich sequence located about 15 nucleotides after the cleavage site (FIG. 1b). Both cleavage reactions preferentially occur after the dinucleotide CA, giving rise to a 3'-hydroxyl (3'-OH), and both reactions occur in vitro in the presence of EDTA, a property that helped identify the canonical histone pre-mRNA cleavage factor ${ }^{19-21}$.

In the first step of histone mRNA $3^{\prime}$ end formation ${ }^{22}$, SlBP binds the stem-loop and then the HDE binds with a novel snRNA, U7 snRNA (a component of the U7 small nuclear ribonucleoprotein, snRNP (FIG. 1b)). U7 snRNA is similar to the spliceosomal snRNAs (U1, $\mathrm{U} 2, \mathrm{U} 4$ and U5) as it has a 2,2,7-trimethylguanylate cap, precipitates with the anti-Sm antisera and ends in a stem-loop. It is the 5' end of U7 snRNA that base-pairs with the $\mathrm{HDE}^{23,24}$. In spliceosomal snRNPs, the seven Sm proteins (SMB, SMB', SMD1, SMD2, SME, SMF and SMG) form a heptameric ring around the Sm-binding site. U7 snRNA contains a slightly different $\mathrm{Sm}$ site, which deviates from the consensus Sm-binding sites in spliceosomal snRNAs at two of the ten positions. Two novel Sm-like proteins, LSM10 and LSM11, replace SMD1 and SMD2 (Refs 25,26) in U7 snRNP, and their inclusion is required to bind the non-consensus Sm-binding site in the U7 snRNA ${ }^{27}$. Changing the novel Sm site in U7 snRNA to the consensus Sm site results in binding of the spliceosomal Sm core structure and inactivation of U7 snRNP27.

Together, SLBP and U7 snRNP recruit a cleavage factor that contains at least CPSF73 (cleavage and polyade-nylation specificty factor 73), CPSF100 and symplekin ${ }^{28}$, and probably also FIP1 (Refs 21,28,29), all of which are also part of the complex that processes the $3^{\prime}$ end of polyadenylated mRNAs. The components of the cleavage factor have been identified by both in vivo and in vitro approaches. CPSF73 can be crosslinked to the cleavage site $^{21}$, and symplekin can restore processing to a heat-treated extract ${ }^{28}$. CPSF73 contains tightly bound zinc, which accounts for the ability of the cleavage reaction to occur in EDTA. A recent study showed that a fusion protein containing CPSF73, CPSF100 and symplekin can restore processing to a heat-treated extract, and that this activity requires crucial residues for zinc binding in CPSF73 and CPSF100 (REF. ${ }^{30}$ ). This provides direct evidence for activity of these proteins in cleavage, and indicates that CPSF73 is almost certainly the endonuclease that cleaves histone pre-mRNA and polyadenylated pre-mRNAs ${ }^{21,31}$. Interestingly, the $3^{\prime}$ end of snRNAs is probably formed through cleavage by an integrator complex containing integrator 9 and 11 subunits that are homologous to CPSF100 and CPSF73, respectively, and that are members of the $\beta$-lactamase family ${ }^{32}$. This suggests that the mechanism for formation of the 3 ' end of all RNA polymerase II transcripts has been conserved.

\section{Histone locus bodies: a factory for histone mRNA synthesis?}

One possible reason for the conserved physical linkage of histone genes is that it allows them to be brought within a domain of the nucleus that is specifically enriched in factors required for the expression of replication-dependent histone genes, for example, the Cajal body. In mammalian cells and frog oocytes, Cajal bodies contain the U7 snRNP 33,34 and, like 'nuclear speckles' that contain splicing factors, they either act as stockpiles of processing factors or are sites of processing. Vertebrate Cajal bodies are also sites of snRNA maturation and snRNP assembly ${ }^{35,36}$. Cajal bodies are found at several sites in the nucleus, including near the mammalian ${ }^{37}$ and frog ${ }^{38}$ replication-dependent histone genes and, in mammals, Cajal bodies located near these genes differ from others as they contain NPAT ${ }^{13,14}$ (FIG. 3).

Recently, Gall and co-workers reported the first example of a Cajal body outside vertebrates by showing that $D$. melanogaster has a single Cajal body in each nucleus ${ }^{39}$. Strikingly, $D$. melanogaster nuclei also contain a separate body, the histone locus body (HLB), that is associated with the replication-dependent histone gene cluster (FIG. 3). The HLB contains factors involved in histone mRNA expression, but does not contain U85 (REF. ${ }^{39}$ ), a small 
RNA required for modification of the spliceosomal snRNAs ${ }^{40}$ that is present in the Cajal body. The Cajal body and the HIB are adjacent to the nucleolus and are occasionally close to each other but are non-overlapping. Thus, in D. melanogaster there are distinct nuclear organelles for snRNA maturation and replication-dependent histone pre-mRNA processing. The HLB can also be visualized with the MPN2 monoclonal antibody, which recognizes a cyclin E-CDK2dependent phospho-epitope in the HLB of D. melanogaster cells ${ }^{41}$, suggesting that flies and mammals have similar cell cycle regulatory inputs into replication-dependent histone gene expression.

\section{Translation of replication-dependent histone mRNA}

Replication-dependent histone mRNAs, like most other mRNAs, are exported from the nucleus by antigen peptide transporter ${ }^{42-44}$, and once exported they are efficiently translated. Translation of polyadenylated mRNA requires that the $3^{\prime}$ poly(A) tail be brought into the proximity of the $5^{\prime}$ cap. This is mediated through protein-protein interactions between the poly (A) binding protein and eukaryotic translation initiation factor 4- $\gamma$ (EIF4G), which also interacts with the cap-binding protein ${ }^{45}$. A distinct mechanism has evolved for the circularization of replication-dependent histone mRNAs. Like the poly(A) tail on other mRNAs, the $3^{\prime}$ end of these histone mRNAs is essential for translation in vivo ${ }^{46}$. SLBP is bound to the cytoplasmic histone $\mathrm{mRNA}^{47}$ and is required for its translation ${ }^{48,49}$. The translation activation region has been mapped to a conserved region of SLBP ${ }^{50}$. SLBP does not interact directly with EIF4G, but the domain required for translation of histone mRNA interacts with the recently identified protein SLIP1, which also interacts with EIF4G ${ }^{50}$. Thus, these proteins circularize histone mRNA and help mediate the efficient translation of histone mRNA by a mechanism similar to the translation of polyadenylated mRNAs.

\section{Regulated degradation of replication-dependent his-tone mRNAs}

As cells approach the end of $\mathrm{S}$ phase, the need for new canonical histone proteins diminishes and the levels of replication-dependent histone mRNAs decrease. This attenuation of mRNA levels is achieved at the level of transcription in the yeast Saccharomyces cerevisiae, in which the half-life of the mRNAs is intrinsically short ${ }^{51}$. By contrast, in mammals the decrease results from a rapid reduction in mRNA half-life when DNA replication is blocked or completed. The stem-loop at the $3^{\prime}$ end of replication-dependent histone mRNAs is the cis-element that mediates this degradation ${ }^{52}$. Degradation requires that the stem-loop be close to the stop $\operatorname{codon}^{53,54}$, which accounts for the observation that in all metazoan histone mRNAs the stemloop begins 25-60 nucleotides from the termination codon. Degradation of histone mRNA requires SLBP, which is involved in recruiting the proteins necessary to add a short oligo(U) tail to the histone mRNA that is being translated ${ }^{55}$. This oligo(U) tail is an optimal binding site for the LSM1-7 heptamer and leads to the degradation of the histone mRNA by pathways that are similar to those involved in the degradation of poly(A) mRNA after deadenylation ${ }^{56,57}$. Thus, both the $3^{\prime}$ ends of replication-dependent histone mRNAs and SLBP are crucial for three steps in histone mRNA metabolism - processing, translation and degradation (FIG. 2).

\section{Cell-cycle regulation of histone mRNAs}

\section{Multiple modes of coordination with the cell cycle}

In mammalian cells, there are four distinct regulatory mechanisms that contribute to the proper rate of canonical histone protein accumulation during the cell cycle: transcription of the histone genes, efficiency of pre-mRNA processing, change in mRNA half-life and degradation of excess histone protein. Replication-dependent histone mRNAs, for all five classes of canonical histones, are among the most highly cell-cycle-regulated mRNAs in mammalian cells. 
Accumulation of replication-dependent histone mRNAs just before entry into $\mathrm{S}$ phase is due to a 3-5-fold increase in the rate of histone gene transcription, and to an increase in the efficiency of histone mRNA processing (the percentage of histone transcripts that reach the cytoplasm). At the end of S phase, histone mRNAs are rapidly degraded and the processing of histone mRNA is inactivated. Of an overall 35 -fold change in replication-dependent histone mRNA levels in Chinese hamster ovary cells, post-transcriptional regulation accounts for about a 10-fold change: histone mRNAs expressed using a constitutive promoter but ending in the replication-dependent histone $3^{\prime}$ end increase 10 -fold as cells enter $\mathrm{S}$ phase and are rapidly degraded at the end of S phase ${ }^{58}$. Thus the stem-loop is the cis-element that determines posttranscriptional regulation of histone mRNA, which largely determines the cell-cycle-regulated expression of canonical histone genes ${ }^{58,59}$. In cells arrested in G1 there is a defect in replication-dependent histone pre-mRNA processing ${ }^{60}$, which is due to a heat-labile factor ${ }^{61}$, 62 that has recently been identified as symplekin ${ }^{28}$, a protein also involved in polyadenylation in vivo ${ }^{63}$.

In continuously cycling mammalian cells SLBP is cell-cycle-regulated (FIG. 4), and this accounts for much of the regulation of replication-dependent histone pre-mRNA processing during the cell cycle. SLBP is synthesized as cells enter S phase and is rapidly degraded at the end of $\mathrm{S}$ phase. This protein is probably bound to mature histone mRNA throughout its lifetime and is required stoichiometrically for histone mRNA function as it participates directly in translation $^{48,50}$ and degradation ${ }^{55,64}$. Thus, levels of SLBP determine the maximal levels of replication-dependent histone mRNA that can accumulate in the cytoplasm. As cells reach the end of S phase, replication-dependent histone mRNA is rapidly degraded, along with SLBP $^{65}$.

Although the levels of SLBP and replication-dependent histone mRNA parallel each other during the cell cycle, the molecular signals that regulate these two factors are distinct. The levels of replication-dependent histone mRNA and DNA replication are tightly coupled during $S$ phase. Thus, inhibiting DNA replication in the middle of $S$ phase results in rapid degradation of replication-dependent histone mRNA, but there is no effect on SLBP levels ${ }^{47}$. In addition, stabilizing SLBP does not prevent replication-dependent histone mRNA degradation at the end of S phase ${ }^{65}$. SLBP degradation at the end of S phase requires activation of cyclin A-CDK1 (REF. ${ }^{66}$ ). Thus, the precise regulation of canonical histone protein synthesis occurs partly by continual adjustment of the half-life of their mRNAs such that transcript levels are appropriate to the demand for canonical histones during DNA replication ${ }^{67}$.

The expression of mRNAs that encode canonical histones is restricted to $S$ phase in all metazoans, suggesting that rapid degradation of replication-dependent histone mRNA at the end of S phase is probably a conserved pathway. However, the degree to which SLBP and 3' end formation are directly regulated during the cell cycle in metazoans other than vertebrates is not as clear. SLBP certainly persists into G2 and the subsequent G1 in early $D$. melanogaster embryos and in imaginal discs ${ }^{68,69}$. This result suggests that, if processing regulation is present in D. melanogaster, the molecular mechanism might be different and regulation of cleavage factor activity might have an important role.

The mRNAs encoding canonical histones in lower eukaryotes and plants are polyadenylated and their accumulation is also restricted to $S$ phase. In yeast, histone mRNA levels are primarily regulated by transcription, and the mRNAs have a short half-life, resulting in their rapid disappearance when transcription is terminated at the end of S phase ${ }^{51}$. The molecular basis of regulation of plant histone mRNA during the cell cycle is not known. Metazoans have clearly evolved a sophisticated post-transcriptional regulatory system using the stem-loop and SLBP as key cis and trans elements. This allows the distinction of histone mRNAs from all other cellular mRNAs and rapid adjustment of histone mRNA levels. 
In addition to regulation of histone mRNAs, there is also a mechanism to degrade excess histone proteins, which probably accumulate during the short time before the cell can degrade histone mRNA at the end of S phase. This system has been characterized in S. cerevisiae, in which targeting of excess histone for degradation involves modification of histone phosphoryla-tion and a protein complex containing the checkpoint kinase RAD53 (REF. ${ }^{70}$ ). The determination of whether a similar system exists in metazoans awaits further studies. This system is likely to be present in all eukaryotes ${ }^{71}$ given the importance of precisely maintaining proper histone protein levels.

\section{A possible histone 'checkpoint' in G1 in mammalian cells}

Mammalian cells have sophisticated regulatory mechanisms, termed 'checkpoints', to ensure they do not progress between stages of the cell cycle in the presence of damaged DNA or with insufficient resources to complete the new phase. Checkpoints act during $\mathrm{S}$ phase, mitosis and G1 to sense the production of sufficient ribosomal proteins for cell growth. Recent evidence supports the possibility of a histone checkpoint in G1 cells. Depleting components of the U7 snRNP in U2OS cells resulted in arrest of cells in G1. In particular, there is a requirement for zinc finger protein 100 (ZFP100), which is a component of the active U7 snRNP ${ }^{72}$, and depletion of this protein results in G1 arrest without affecting U7 snRNA levels. By contrast, depletion of SLBP does not cause G1 arrest but rather accumulation of cells in S phase ${ }^{73}$. These results suggest that the presence of an active U7 snRNP is essential for progression through G1 and entry into S phase.

\section{Crosstalk in histone metabolism}

A crucial aspect of chromatin structure and function is the incorporation of proper proportions of the different histone variants to maintain the global organization of chromatin domains that determines which genes are active. We recently reported the surprising finding that the synthesis of histone variants $\mathrm{H} 3.3$ and $\mathrm{H} 2 \mathrm{Av}$ is coupled to the expression of the replicationdependent histone mRNAs by modulation of the processing of pre-mRNAs encoding the canonical histones ${ }^{29}$. In a genome-wide RNAi screen in D. melanogaster these proteins were identified as being required for replication-dependent histone pre-mRNA processing. The same study showed that $D$. melanogaster lacking $\mathrm{H} 2 \mathrm{Av}$ form some misprocessed, polyadenylated replication-dependent histone mRNAs. Interestingly, incorporation of U7 snRNP into the HLB is reduced in $\mathrm{H} 2 \mathrm{Av}$ mutants or in cultured cells with $\mathrm{H} 2 \mathrm{Av}$ knocked down, suggesting that the defect is a failure to concentrate the replication-dependent histone pre-mRNA processing machinery at the histone gene cluster, resulting in inefficient formation of the $3^{\prime}$ end of the mRNA.

How might the histone variants $\mathrm{H} 2 \mathrm{Av}$ and $\mathrm{H} 3.3$ affect canonical histone mRNA 3' end formation? one possibility is that they might act directly as an essential component of chromatin at loci encoding canonical histones (FIG. 5). This implies that the presence of specific histone variants within nucleosomes at the canonical histone locus is necessary for efficient recruitment or retention of the U7 snRNP in the HLB (that is, the variants act in cis). This model has similarities to the role of the centromeric variant $\mathrm{H} 3$ histone (CID in D. melanogaster): specific localization of $\mathrm{H} 3$ to centromeres is necessary for recruitment of kinetochore proteins ${ }^{74}$.

Alternatively, the lack of sufficient amounts of the $\mathrm{H} 2 \mathrm{Av}$ or $\mathrm{H} 3.3$ variants in bulk chromatin could elicit a signal that dampens production of core histones by inhibiting HLB formation to prevent $3^{\prime}$ end processing (that is, the variants act in trans) (FIG. 5). One step in histone metabolism where the canonical histone $\mathrm{H} 3$ and the $\mathrm{H} 3.3$ variants share a common factor is in chromatin assembly. The H3.3-H4 dimer is assembled into chromatin by an assembly factor containing HIRA $^{75}$, whereas the CAF1 chromatin assembly complex ${ }^{76}$ assembles canonical histones into chromatin ${ }^{75}$. The H2A.Z protein in yeast is selectively assembled into chromatin 
by a complex containing CHZ1 (REF. ${ }^{77}$ ), and a candidate orthologous protein is present in other metazoans. It is possible that cells keep these assembly complexes loaded with histone protein at all times.

If there is a deficiency of variant histone protein synthesis, the HIRA or CHZ1 complex might be depleted of histone protein and this could generate a signal that downregulates expression of the replication-dependent histones at the level of 3 ' end processing. ASF1, a chromatin assembly factor present in multiple complexes, was identified in the screen for factors required for histone $3^{\prime}$ end formation ${ }^{29}$ and has a crucial role in regulating DNA replication ${ }^{78}$. ASF1 is a component of the CAF1, HIRA and CHZ1 chromatin assembly complexes and hence might be a central player that modulates the activity of all the different chromatin assembly complexes. It might also directly participate in regulation of replication-dependent histone preRNA processing. Interestingly, ASF1 is highly enriched at the histone gene cluster of $D$. melanogaster polytene chromosomes ${ }^{79}$, which is consistent with a direct role in canonical histone gene expression.

\section{Regulation during early development}

Immediately after fertilization, metazoan zygotes - which do not synthesize DNA but contain a store of factors necessary for chromatin replication - initiate the biochemical pathways necessary for chromosome replication. Following fertilization, sperm chromatin is remodelled and histone proteins stored in the oocyte package the sperm $\mathrm{DNA}^{80,81}$. In many organisms in which the embryo develops outside the mother (amphibians, insects, echinoderms and some fish), early development is characterized by a rapid series of nuclear replications, increasing the amount of chromatin in the embryo between one-hundred-fold and several-thousand-fold in a few hours. These cell cycles are often characterized by alternating $\mathrm{S}$ and $\mathrm{m}$ cell cycles that lack gap phases. There is also generally no growth of the embryo during this time, and there is often no transcription. Thus, all components necessary for early development must be stored in the oocyte or unfertilized egg and gene expression is regulated at the translational level. In many of these species the development to the larval (feeding) stage must occur without any outside source of nutrients ${ }^{82}$.

During this time the demand for histone proteins in many species is greater than at any other stage of the life cycle of the organism, and this demand may be met by storage of appropriate amounts of histone proteins or mRNAs. The oocyte must produce these components and store them in an inactive form. Different organisms use distinct strategies to meet this demand for histone synthesis during early development, controlling the changes in histone metabolism that take place as the oocyte matures to become the egg and during the development of the early embryo (FIG. 6). Again, the unique 3' end of histone mRNAs has a major role in these strategies.

In D. melanogaster, histone proteins are stored in the egg in sufficient amounts for development to proceed to the several thousand cell stage, by which time transcription is activated (FIG. 5). During this time, the canonical histones are present in a complex with histone chaperones (N1$\mathrm{N} 2$ for $\mathrm{H} 3-\mathrm{H} 4$ and nucleoplasmin for $\mathrm{H} 2 \mathrm{~A}-\mathrm{H} 2 \mathrm{~B})^{83}$, which are histone storage proteins. The mRNA used to synthesize these embryonic histone proteins is synthesized by the nurse cells in a small window of time at the end of oogenesis ${ }^{84,85}$ following the final round of endoreplication. As suggested earlier, the large numbers of copies of the D. melanogaster canonical histone genes may be necessary at this stage to produce sufficient amounts of protein. SLBP and U7 snRNA are both required during oogenesis ${ }^{68,86}$ to provide the egg with maternal histone mRNA, which persists for about 2 hours in the early embryo ${ }^{68}$. Zygotic synthesis of histone mRNA begins after this time. In SLBP-null mutants substantial amounts of 
misprocessed histone mRNA accumulate when histone gene transcription initiates, suggesting that there is only a small supply of functional maternal SLBP ${ }^{68}$.

Xenopus laevis uses a different strategy to solve the same problem. Much more canonical histone protein must be provided: 100-1000 times more, owing to both the larger genome size and the greater number of cell cycles before transcription initiates. Both histone mRNA and protein accumulate during early oogenesis ${ }^{87}$. In mature oocytes the large amounts of histone mRNA are not translated because they are bound by an oocyte-specific SLBP, xSLBP2 (Refs 48,88 ). xSLBP2 has a similar RBD to XSLBP1, but crucially it lacks the domain that is required for translational activation and interaction with XSIIP1, which activates translation. Hence xSLBP2 represses translation when it is bound to histone mRNA. xSLBP2 is degraded within 6 hours after treatment with progesterone to initiate oocyte maturation and before germinal vesicle breakdown, which allows XSLBP1 to bind and activate translation, thereby initiating histone protein synthesis ${ }^{89}$. This approach of having two SLBPs seems to be an evolutionary invention in amphibians as no other species (including zebrafish, which face similar developmental challenges as frogs during the early cleavage stages) encode a second SLBP to store inactive histone mRNA.

Sea urchins have a set of replication-dependent histone genes that are tandemly repeated (400 copies) and are active only in early embryogenesis. Sea urchins do not store canonical histone proteins in the unfertilized egg, although they do store a set of variant 'cleavage-stage' histones encoded by polyadenylated histone mRNAs that package the chromatin during remodelling of the sperm chromatin and the first 2-4 cell cycles ${ }^{90}$. The tandemly repeated genes are not transcribed in oogenesis but are transcribed in the unfertilized egg, where the mRNAs are processed but retained in the pronucleus ${ }^{91}$. The mRNAs are released into the cytoplasm at the first cell division. Transcription of these histone genes continues through the rapid initial cleavage cycles and provides the templates for histone protein synthesis for the early embryo; the genes are then silenced. There is a second set of replication-dependent histone genes in sea urchins, termed the 'late' histone genes, containing about 10 non-allelic copies of each histone gene $^{92}$. These 'late' histone genes are the only histone genes expressed in later development and the rest of the life of the animal ${ }^{93}$ and are similar to the mammalian replication-dependent histone genes ${ }^{92}$.

Mammals have evolved yet another mechanism of regulating the onset of canonical histone protein production in early development. Replication-dependent histone mRNAs stored in the oocyte are not translated, possibly because of low levels of SLBP ${ }^{94}$. At oocyte maturation, SLBP mRNA is translated, resulting in a large increase in SLBP protein and activation of histone mRNA translation. This pathway is essential for providing the initial supply of histone protein as blocking SLBP production in the oocyte prevents development ${ }^{95}$.

\section{The origin of non-polyadenylated histone mRNAs}

Until recently, the unique family of non-polyadenylated canonical histone mRNAs was thought to be present only in metazoans, with the exception of organisms that are difficult to classify, such as Volvox carter $^{96}$ and Chlamydomonas reinhardtii ${ }^{97}$, suggesting that histone mRNAs ending in stem-loops might have arisen relatively late in evolution, after the divergence of plants and animals. In addition, SLBP had not been reported in species other than those known to contain histone genes ending in stem-loops. There are no homologues of SLBP with a similar RBD in any organism, making this a unique protein. It is likely that SLBP functions only in replication-dependent histone mRNA metabolism, as no other mammalian mRNAs contain the stem-loop or bind to SLBP ${ }^{98}$.

Recently, Samuelsson and co-workers reported the surprising finding of a protein with sequences homologous to the RBD of SLBP in several protozoa, including species from the 
deeply branching Trichomonas and Euglenozoa genera ${ }^{99}$. Closer inspection of the canonical histone genes in these organisms revealed a potential stem-loop structure in the $3^{\prime}$ UTR (FIG. 1c) that was similar to that found in metazoans. Some of these stem-loop sequences have diverged substantially from the metazoan sequence, although they all contain the crucial elements required for recognition by metazoan SLBP: a GC base pair at position 2 of the $\mathrm{stem}^{5}$, and a $\mathrm{U}$ at position 3 of the loop. These potential stem-loop sequences were only present in organisms that contain the SLBP orthologue. Unlike metazoans, in these species the stemloops are not constrained in terms of being close to the termination codon. In addition, other than in Volvox carteri and C. reinhardtii, there is no direct evidence addressing whether the stem-loop is present at the end of the histone mRNAs in the $3^{\prime}$ UTR. It is more difficult to judge whether there is a U7 snRNP in these species, as this complex is difficult to identify unambiguously even in some metazoans. Approximately $10 \%$ of the protozoan genomes that have been sequenced and analysed contain the SLBP orthologues and stem-loops downstream of the canonical histone genes.

Given the above findings, SLBP and stem-loops that probably bind SLBP in the 3' UTRs of histone mRNAs must have appeared early in eukaryotic evolution. It is likely that SLBP was involved in some aspect of regulation of histone mRNA metabolism early in evolution, which could include pre-mRNA processing. This system seems to have been lost in many species but retained in isolated representatives in most phyla. In metazoans, additional roles have evolved for SLBP and the stem-loop in the metabolism and regulation of canonical histone mRNAs, including the development of the mRNA degradation system that depends on the stem-loop being close to the termination codon.

\section{Conclusions}

Replication-dependent mRNAs that encode the canonical histones are the only cellular nonpolyadenylated mRNAs. Their unique $3^{\prime}$ end structure, containing a conserved stem-loop bound by SLBP, is the key feature that permits the coordinated synthesis of the canonical histones. This feature is crucial for the cell cycle regulation of the mRNA and for the regulation of histone production in early development in many metazoans. Unexpectedly, many of the same factors are involved in the expression of both replication-dependent histone mRNAs and polyadenylated mRNAs, and a relatively small number of specific factors are necessary for the metabolism of canonical histone mRNAs.

Recent evidence suggests that the specialized 3' end of replication-dependent histone mRNAs originated early in the evolution of eukaryotes but was completely lost in several lineages, including plants, fungi and most protozoa. Instead, these species synthesize histones from cellcycle-regulated polyadenylated mRNAs, and regulation is primarily at the level of transcription. This raises an interesting question: why has the stem-loop mechanism been retained in all metazoa? one possibility is that the stem-loop system evolved the ability to coordinately regulate histone mRNAs post-transcriptionally, in addition to the existing transcriptional regulation, and that this property was selected for in metazoans. In extant metazoans, this feature provides a sophisticated mechanism for coordinate regulation of histone mRNAs and rapid adjustment of histone mRNA levels by changing the half-life of the histone mRNA as the rate of DNA replication changes.

Much remains to be learned about the biochemical details of the pathways required for canonical histone mRNA expression and function in terms of the unique modes of processing, translation and degradation that result from the presence of a stem-loop rather than a poly(A) tail at the $3^{\prime}$ end of the mRNA. In addition, we do not yet understand the precise signalling pathways that coordinate histone synthesis in the cytoplasm and DNA replication in the 
nucleus, or how histone mRNA regulation is integrated into the overall network of cell cycle regulation. Future work is likely to focus on these crucial issues.

\section{DATABASES}

UniProtKB: http://www.uniprot.org

CENPA | H1.0 | H2A.X | H2A.Z | H3.3 | NPAT | SLBP | SLIP1

\section{FURTHER INFORMATION}

\section{W. M. Marzluff's homepage:}

www.bio.unc.edu/faculty/marzluff

Duronio laboratory homepage:

www.bio.unc.edu/faculty/duronio/lab

ALL LINKS ARE ACTIVE IN THE ONLINE PDF

\section{Glossary}

Small nuclear RNA(snRNA), A series of small nuclear RNAs are involved in pre-mRNA processing.; Cajal body, An organelle in the nucleus, characterized by the presence of the protein coilin, that contains many factors needed for snRNA biosynthesis and in vertebrates also contains U7 snRNP.; Spliceosome, The complex of small nuclear ribonucleoproteins and associated proteins that removes introns from pre-mRNAs.; Nucleolus, An organelle in the nucleus that primarily functions in ribosome biosynthesis.; Nurse cells, There are 16 germ cells in each D. melanogaster egg chamber (or follicle). One differentiates into the oocyte and the other 15 become highly polyploid nurse cells that synthesize much of the RNA and protein incorporated into the oocyte.; Endoreplication, Process of polyploidization of the genome in which repeated rounds of s phase occur without an intervening mitosis.; Germinal vesicle, The oocyte nucleus (4C) before meiosis.; Pronucleus, The haploid nucleus (1C) present in the egg after meiosis..

\section{References}

1. Henikoff S, Ahmad K. Assembly of variant histones into chromatin. Annu. Rev. Cell Dev. Biol 2005;21:133-153. [PubMed: 16212490]

2. Groth A, Rocha W, Verreault A, Almouzni G. Chromatin challenges during DNA replication and repair. Cell 2007;128:721-733. [PubMed: 17320509]

3. De KL, Corpet A, Haber JE, Almouzni G. Histone chaperones: an escort network regulating histone traffic. Nature Struct. Mol. Biol 2007;14:997-1007. [PubMed: 17984962]

4. Marzluff WF. Metazoan replication dependent histone mRNAs: a unique class of RNA polymerase II transcripts. Curr. Opin. Cell Biol 2005;17:274-280. [PubMed: 15901497]

5. Battle DJ, Doudna JA. The stem-loop binding protein forms a highly stable and specific complex with the 3' stem-loop of histone mRNAs. RNA 2001;7:123-132. [PubMed: 11214174]

6. Wang Z-F, Whitfield ML, Ingledue TI, Dominski Z, Marzluff WF. The protein which binds the $3^{\prime}$ end of histone mRNA: a novel RNA-binding protein required for histone pre-mRNA processing. Genes Dev 1996;10:3028-3040. [PubMed: 8957003]

7. Roberts SB, Sanicola M, Emmons SW, Childs G. Molecular characterization of the histone gene family of Caenorhabditis elegans. J. Mol. Biol 1987;196:27-38. [PubMed: 3656446]

8. Marzluff WF, Gongidi P, Woods KR, Jin JP, Maltais L. The human and mouse replication-dependent histone genes. Genomics 2002;80:487-498. [PubMed: 12408966] 
9. Thiriet C, Hayes JJ. Chromatin in need of a fix: phosphorylation of H2AX connects chromatin to DNA repair. Mol. Cell 2005;18:617-622. [PubMed: 15949437]

10. Mannironi C, Bonner WM, Hatch CL. H2A.X, a histone isoprotein with a conserved C-terminal sequence, is encoded by a novel mRNA with both DNA replication type and polyA $3^{\prime}$ processing signals. Nucleic Acids Res 1989;17:9113-9126. [PubMed: 2587254]

11. Wu RS, Bonner WM. Separation of basal histone synthesis from $\mathrm{S}$ phase histone synthesis in dividing cells. Cell 1981;27:321-330. [PubMed: 7199388]

12. DeLisle AJ, Graves RA, Marzluff WF, Johnson LF. Regulation of histone mRNA production and stability in serum stimulated mouse fibroblasts. Mol. Cell. Biol 1983;3:1920-1929. [PubMed: 6656760]

13. Ye X, Wei Y, Nalepa G, Harper JW. The cyclin E/Cdk2 substrate p $220^{\mathrm{NPAT}}$ is required for S-phase entry, histone gene expression, and Cajal body maintenance in human somatic cells. Mol. Cell Biol 2003;23:8586-8600.8600 [PubMed: 14612403] This paper shows that NPAT, a factor present in the Cajal body associated with vertebrate histone genes, is essential and necessary not only for histone gene expression but also for entry into $\mathrm{S}$ phase and maintenance of Cajal bodies.

14. Ma TL, et al. Cell cycle-regulated phosphorylation of $\mathrm{p} 220^{\mathrm{NPAT}}$ by cyclin E/Cdk2 in Cajal bodies promotes histone gene transcription. Genes Dev 2000;14:2298-2313. [PubMed: 10995387]

15. Wei Y, Jin J, Harper JW. The cyclin E/Cdk2 substrate and Cajal body component p $220^{\text {NPAT }}$ activates histone transcription through a novel LisH-like domain. Mol. Cell Biol 2003;23:3669-3680. [PubMed: 12724424]

16. Zhao JY, et al. NPAT links cyclin E-Cdk2 to the regulation of replication-dependent histone gene transcription. Genes Dev 2000;14:2283-2297. [PubMed: 10995386]

17. Pandey NB, Chodchoy N, Liu T-J, Marzluff WF. Introns in histone genes alter the distribution of $3^{\prime}$ ends. Nucleic Acids Res 1990;18:3161-3170. [PubMed: 2356116]

18. Mandel CR, Bai Y, Tong L. Protein factors in pre-mRNA 3'-end processing. Cell Mol. Life Sci. 2007

19. Ryan K, Calvo O, Manley JL. Evidence that polyadenylation factor CPSF-73 is the mRNA 3' processing endonuclease. RNA 2004;10:565-573. [PubMed: 15037765]

20. Scharl EC, Steitz JA. The site of $3^{\prime}$ end formation of histone messenger RNA is a fixed distance from the downstream element recognized by the U7 snRNP. EMBO J 1994;13:2432-2440. [PubMed: 8194533]

21. Dominski Z, Yang XC, Marzluff WF. The polyadenylation factor CPSF-73 is involved in histone pre-mRNA processing. Cell 2005;123:37-48.48 [PubMed: 16213211] This paper shows that CPSF73 crosslinks to the cleavage site in histone pre-mRNA, implicating it as the nuclease in histone premRNA processing.

22. Dominski Z, Marzluff WF. Formation of the 3 ' end of histone mRNA: getting closer to the end. Gene 2007;396:373-390. [PubMed: 17531405]

23. Strub K, Birnstiel ML. Genetic complementation in the Xenopus oocyte: co-expression of sea urchin histone and U7 RNAs restores 3' processing of H3 pre-mRNA in the oocyte. EMBO J 1986;5:16751682.1682 [PubMed: 2943587] This paper provides the first demonstration that a small snRNA is required for processing of histone mRNA in vivo, and that base-pairing to the region downstream of the HDE is necessary for processing.

24. Mowry KL, Steitz JA. Identification of the human U7 snRNP as one of several factors involved in the 3' end maturation of histone premessenger RNA's. Science 1987;238:1682-1687.1687 [PubMed: 2825355] Identification of the human U7 snRNP as an essential component of processing in humans.

25. Pillai RS, Will CL, Lührmann R, Schümperli D, Müller B. Purified U7 snRNPs lack the Sm proteins D1 and D2 but contain Lsm10, a new 14 kDa Sm D1-like protein. EMBO J 2001;20:5470-5479. [PubMed: 11574479]

26. Pillai RS, et al. Unique Sm core structure of U7 snRNPs: assembly by a specialized SMN complex and the role of a new component, Lsm11, in histone RNA processing. Genes Dev 2003;17:23212333.2333 [PubMed: 12975319] References 25 and 26 report the characterization of LSM10 and LSM11, two novel components of the Sm ring in U7 snRNP.

27. Grimm C, Stefanovic B, Schümperli D. The low abundance of U7 snRNA is partly determined by its Sm binding site. EMBO J 1993;12:1229-1238. [PubMed: 8458335] 
28. Kolev NG, Steitz JA. Symplekin and multiple other polyadenylation factors participate in 3 '-end maturation of histone mRNAs. Genes Dev 2005;19:2583-2592.2592 [PubMed: 16230528] This paper demonstrate that symplekin is an essential component for histone pre-mRNA processing in human cells in vitro.

29. Wagner EJ, et al. A genome-wide RNA interference screen reveals that variant histones are necessary for replication-dependent histone pre-mRNA processing. Mol. Cell 2007;28:692-699.699 [PubMed: 18042462] This paper identifies factors required for histone pre-mRNA processing in $D$. melanogaster in vivo, identifying four of 14 polyadenylation factors, as well a connection between the levels of replacement histone proteins and the processing of replication-dependent histone mRNAs.

30. Kolev NG, Yario TA, Benson E, Steitz JA. Conserved motifs in both CPSF73 and CPSF100 are required to assemble the active endonuclease for histone mRNA 3'-end maturation. EMBO Rep. 2008 Aug 8;

31. Mandel CR, et al. Polyadenylation factor CPSF-73 is the pre-mRNA 3'-end-processing endonuclease. Nature 2006;444:953-956. [PubMed: 17128255]

32. Baillat D, et al. Integrator, a multiprotein mediator of small nuclear RNA processing, associates with the C-terminal repeat of RNA polymerase II. Cell 2005;123:265-276. [PubMed: 16239144]

33. Handwerger KE, Gall JG. Subnuclear organelles: new insights into form and function. Trends Cell Biol 2006;16:19-26. [PubMed: 16325406]

34. Ogg SC, Lamond AI. Cajal bodies and coilin — moving towards function. J. Cell Biol 2002;159:1721. [PubMed: 12379800]

35. Cioce M, Lamond AI. Cajal bodies: a long history of discovery. Annu. Rev. Cell Dev. Biol 2005;21:105-131. [PubMed: 16212489]

36. Kiss T. Biogenesis of small nuclear RNPs. J. Cell Sci 2004;117:5949-5951. [PubMed: 15564372]

37. Frey MR, Matera AG. Coiled bodies contain U7 small nuclear RNA and associate with specific DNA sequences in interphase human cells. Proc. Natl. Acad. Sci. USA 1995;92:5915-5919. [PubMed: 7597053]

38. Callan HG, Gall JG, Murphy C. Histone genes are located at the sphere loci of Xenopus lampbrush chromosomes. Chromosoma 1991;101:245-251. [PubMed: 1773662]

39. Liu JL, et al. The Drosophila melanogaster Cajal body. J. Cell Biol 2006;172:875-884.884 [PubMed: 16533947] This paper reports the D. melanogaster Cajal body as well as the HLB, a structure at $D$. melanogaster histone genes that contains U7 snRNP.

40. Jady BE, et al. Modification of Sm small nuclear RNAs occurs in the nucleoplasmic Cajal body following import from the cytoplasm. EMBO J 2003;22:1878-1888. [PubMed: 12682020]

41. White AE, Leslie ME, Calvi BR, Marzluff WF, Duronio RJ. Developmental and cell cycle regulation of the Drosophila histone locus body. Mol. Biol. Cell 2007;18:2491-2502. [PubMed: 17442888]

42. Erkmann JA, Sanchez R, Treichel N, Marzluff WF, Kutay U. Nuclear export of metazoan replicationdependent histone mRNAs is dependent on RNA length and is mediated by TAP. RNA 2005;11:4558. [PubMed: 15611298]

43. Huang YQ, Steitz JA. Splicing factors SRp20 and 9G8 promote the nucleocytoplasmic export of mRNA. Mol. Cell 2001;7:899-905. [PubMed: 11336712]

44. Huang Y, Gattoni R, Stevenin J, Steitz JA. SR splicing factors serve as adapter proteins for TAPdependent mRNA export. Mol. Cell 2003;11:837-843. [PubMed: 12667464]

45. Wells SE, Hillner PE, Vale RD, Sachs AB. Circularization of mRNA by eukaryotic translation initiation factors. Mol. Cell 1998;2:135-140. [PubMed: 9702200]

46. Gallie DR, Lewis NJ, Marzluff WF. The histone 3'-terminal stem-loop is necessary for translation in Chinese hamster ovary cells. Nucleic Acids Res 1996;24:1954-1962. [PubMed: 8657580]

47. Whitfield ML, et al. SLBP is associated with histone mRNA on polyribosomes as a component of histone mRNP. Nucleic Acids Res 2004;32:4833-4842. [PubMed: 15358832]

48. Sanchez R, Marzluff WF. The stem-loop binding protein is required for efficient translation of histone mRNA in vivo and in vitro. Mol. Cell. Biol 2002;22:7093-7104. [PubMed: 12242288]

49. Gorgoni B, et al. The stem-loop binding protein stimulates histone translation at an early step in the initiation pathway. RNA 2005;11:1030-1042. [PubMed: 15987814] 
50. Cakmakci NG, Lerner RS, Wagner EJ, Zheng L-X, Marzluff WF. SLIP1, a factor required for activation of histone mRNA translation by the stem-loop binding protein. Mol. Cell Biol 2008;28:1182-1194. [PubMed: 18025107]

51. Osley MA. The regulation of histone synthesis in the cell cycle. Annu. Rev. Biochem 1991;60:827861. [PubMed: 1883210]

52. Pandey NB, Marzluff WF. The stem-loop structure at the $3^{\prime}$ end of histone mRNA is necessary and sufficient for regulation of histone mRNA stability. Mol. Cell. Biol 1987;7:4557-4559. [PubMed: 3437896]

53. Kaygun H, Marzluff WF. Translation termination is involved in histone mRNA degradation when DNA replication is inhibited. Mol. Cell Biol 2005;25:6879-6888. [PubMed: 16055702]

54. Graves RA, Pandey NB, Chodchoy N, Marzluff WF. Translation is required for regulation of histone mRNA degradation. Cell 1987;48:615-626. [PubMed: 3028643]

55. Mullen TE, Marzluff WF. Degradation of histone mRNA requires oligouridylation followed by decapping and simultaneous degradation of the mRNA both $5^{\prime}$ to $3^{\prime}$ and $3^{\prime}$ to $5^{\prime}$. Genes Dev 2008;22:50-65. [PubMed: 18172165]

56. Tharun $\mathrm{S}$, et al. Yeast Sm-like proteins function in mRNA decapping and decay. Nature 2000;404:515-518. [PubMed: 10761922]

57. Parker R, Song H. The enzymes and control of eukaryotic mRNA turnover. Nature Struct. Mol. Biol 2004;11:121-127. [PubMed: 14749774]

58. Harris ME, et al. Regulation of histone mRNA in the unperturbed cell cycle: Evidence suggesting control at two posttranscriptional steps. Mol. Cell. Biol 1991;11:2416-2424. [PubMed: 2017161]

59. Lüscher B, Stauber C, Schindler R, Schümperli D. Faithful cell-cycle regulation of a recombinant mouse histone $\mathrm{H} 4$ gene is controlled by sequences in the 3'-terminal part of the gene. Proc. Natl Acad. Sci. USA 1985;82:4389-4393. [PubMed: 3925455]

60. Stauber C, Schümperli D. 3' processing of pre-mRNA plays a major role in proliferation-dependent regulation of histone gene expression. Nucleic Acids Res 1988;16:9399-9413. [PubMed: 3141900]

61. Lüscher B, Schümperli D. RNA 3' processing regulates histone mRNA levels in a mammalian cell mutant. A processing factor becomes limiting in G1-arrested cells. EMBO J 1987;6:1721-1726. [PubMed: 3608992]

62. Gick O, Krämer A, Vasserot A, Birnstiel ML. Heat-labile regulatory factor is required for 3' processing of histone precursor mRNAs. Proc. Natl Acad. Sci. USA 1987;84:8937-8940. [PubMed: 2962194]

63. Takagaki Y, Manley JL. Complex protein interactions within the human polyadenylation machinery identify a novel component. Mol. Cell. Biol 2000;20:1515-1525. [PubMed: 10669729]

64. Kaygun, H.; Marzluff, WF. Maquat, LE. Nonsense-Mediated mRNA Decay. Georgetown, Texas: Landes Bioscience; 2006. p. 237-252.

65. Zheng L-X, et al. Phosphorylation of SLBP on two threonines triggers degradation of SLBP, the sole cell-cycle regulated factor required for regulation of histone mRNA processing, at the end of S-phase. Mol. Cell Biol 2003;23:1590-1601. [PubMed: 12588979]

66. Koseoglu MM, Graves LM, Marzluff WF. Phosphorylation of threonine 61 by cyclin A/Cdk1 triggers degradation of stemloop binding protein at the end of S-phase. Mol. Cell. Biol 2008;28:4469-4479. [PubMed: 18490441]

67. Sariban E, Wu RS, Erickson LC, Bonner WM. Interrelationships of protein and DNA syntheses during replication of mammalian cells. Mol. Cell. Biol 1985;5:1279-1286. [PubMed: 4033653]

68. Lanzotti DJ, Kaygun H, Yang X, Duronio RJ, Marzluff WF. Developmental control of histone mRNA and dSLBP synthesis during Drosophila embryogenesis and the role of dSLBP in histone mRNA 3' processing in vivo. Mol. Cell Biol 2002;22:2267-2282. [PubMed: 11884612]

69. Lanzotti DJ, et al. Drosophila stem-loop binding protein intracellular localization is mediated by phosphorylation and is required for cell cycle-regulated histone mRNA expression. Mol. Biol. Cell 2004;15:1112-1123. [PubMed: 14999087]

70. Gunjan A, Verreault A. A Rad53 kinase-dependent surveillance mechanism that regulates histone protein levels in S. cerevisiae. Cell 2003;115:537-549. [PubMed: 14651846]

71. Gunjan A, Paik J, Verreault A. The emergence of regulated histone proteolysis. Curr. Opin. Genet. Dev 2006;16:112-118. [PubMed: 16510276] 
72. Wagner EJ, Marzluff WF. ZFP100, a component of the active U7 snRNP limiting for histone premRNA processing, is required for entry into S-phase. Mol. Cell. Biol 2006;26:6702-6712. [PubMed: 16914750]

73. Wagner EJ, Berkow A, Marzluff WF. Expression of an RNAi-resistant SLBP restores proper S-phase progression. Biochem. Soc. Trans 2005;33:471-473. [PubMed: 15916543]

74. Henikoff S, Dalal Y. Centromeric chromatin: what makes it unique? Curr. Opin. Genet. Dev 2005;15:177-184. [PubMed: 15797200]

75. Tagami H, Ray-Gallet D, Almouzni G, Nakatani Y. Histone H3.1 and H3.3 complexes mediate nucleosome assembly pathways dependent or independent of DNA synthesis. Cell 2004;116:51-61. [PubMed: 14718166]

76. Ye X, et al. Defective $S$ phase chromatin assembly causes DNA damage, activation of the S phase checkpoint, and S phase arrest. Mol. Cell 2003;11:341-351. [PubMed: 12620223]

77. Luk E, et al. Chz1, a nuclear chaperone for histone H2AZ. Mol. Cell 2007;25:357-368. [PubMed: 17289584]

78. Groth A, et al. Human Asf1 regulates the flow of S phase histones during replicational stress. Mol. Cell 2005;17:301-311. [PubMed: 15664198]

79. Moshkin YM, et al. Histone chaperone ASF1 cooperates with the Brahma chromatin-remodelling machinery. Genes Dev 2002;16:2621-2626. [PubMed: 12381660]

80. Philpott A, Leno GH. Nucleoplasmin remodels sperm chromatin in Xenopus egg extracts. Cell 1992;69:759-767. [PubMed: 1591776]

81. McLay DW, Carroll J, Clarke HJ. The ability to develop an activity that transfers histones onto sperm chromatin is acquired with meiotic competence during oocyte growth. Dev. Biol 2002;241:195-206. [PubMed: 11784105]

82. Woodland HR. The translational control phase of early development. Biosci. Rep 1982;2:471-491. [PubMed: 7052156]

83. Dilworth SM, Black SJ, Laskey RA. Tw o complexes that contain histones are required for nucleosome assembly in vitro: role of nucleoplasmin and N1 in Xenopus egg extracts. Cell 1987;51:1009-1018. [PubMed: 3690659]

84. Ruddell A, Jacobs-Lorena M. Biphasic pattern of histone gene expression during Drosophila oogenesis. Proc. Natl Acad. Sci. USA 1985;82:3316-3319. [PubMed: 3923476]

85. Walker J, Bownes M. The expression of histone genes during Drosophila melanogaster oogenesis. Dev. Genes Evol 1998;207:535-541. [PubMed: 9510548]

86. Godfrey AC, et al. U7 snRNA mutations in Drosophila block histone pre-mRNA processing and block oogenesis. RNA 2006;12:396-409. [PubMed: 16495235]

87. Turner PC, Woodland HR. Histone gene number and organisation in Xenopus: Xenopus borealis has a homogeneous major cluster. Nucleic Acids Res 1983;11:971-986. [PubMed: 6298735]

88. Wang Z-F, Ingledue TC, Dominski Z, Sanchez R, Marzluff WF. Two Xenopus proteins that bind the $3^{\prime}$ end of histone mRNA: Implications for translational control of histone synthesis during oogenesis. Mol. Cell. Biol 1999;19:835-845.845 [PubMed: 9858606] This paper shows that there is a second SLBP in $X$. laevis that participates in the control of histone mRNA translation in oogenesis.

89. Sánchez R, Marzluff WF. The oligoA tail on histone mRNA plays an active role in translational silencing of histone mRNA during Xenopus oogenesis. Mol. Cell. Biol 2004;24:2513-2525. [PubMed: 14993288]

90. Mandl B, et al. The five cleavage-stage (CS) histones of the sea urchin are encoded by a maternally expressed family of replacement histone genes: Functional equivalence of the CS H1 and frog H1M (B4) proteins. Mol. Cell. Biol 1997;17:1189-1200. [PubMed: 9032246]

91. Venezky DL, Angerer LM, Angerer RC. Accumulation of histone repeat transcripts in the sea urchin egg pronucleus. Cell 1981;24:385-391. [PubMed: 7195316]

92. Marzluff WF, Sakallah S, Kelkar H. The sea urchin histone gene complement. Dev. Biol 2006;300:308-320. [PubMed: 17078943]

93. Maxson R, Mohun TJ, Cohn R, Kedes L. Expression and organization of histone genes. Annu. Rev. Genet 1983;17:239-277. [PubMed: 6421226] 
94. Allard P, Yang Q, Marzluff WF, Clarke HJ. The stem-loop binding protein regulates translation of histone mRNA during mammalian oogenesis. Dev. Biol 2005;286:195-206. [PubMed: 16125165]

95. Arnold DR, Francon P, Zhang J, Martin K, Clarke HJ. Stem-loop binding protein expressed in growing oocytes is required for accumulation of mRNAs encoding histones $\mathrm{H} 3$ and $\mathrm{H} 4$ and for early embryonic development in the mouse. Dev. Biol 2008;313:347-358. [PubMed: 18036581]

96. Müller K, Lindauer A, Brüderlein M, Schmitt R. Organization and transcription of Volvox histoneencoding genes: Similarities between algal and animal genes. Gene 1990;93:167-175. [PubMed: 2227431]

97. Fabry S, et al. The organization structure and regulatory elements of Chlamydomonas histone genes reveal features linking plant and animal genes. Curr. Genet 1995;28:333-345. [PubMed: 8590479]

98. Townley-Tilson WH, Pendergrass SA, Marzluff WF, Whitfield ML. Genome-wide analysis of mRNAs bound to the histone stem-loop binding protein. RNA 2006;12:1853-1867. [PubMed: 16931877]

99. Lopez MD, Samuelsson T. Early evolution of histone mRNA 3' end processing. RNA 2008;14:1-10. [PubMed: 17998288]

100. Yang XC, Purdy M, Marzluff WF, Dominski Z. Characterization of 3'hExo, a 3' exonuclease specifically interacting with the 3' end of histone mRNA. J. Biol. Chem 2006;281:30447-30454. [PubMed: 16912046]

101. Whitfield ML, et al. Stem-loop binding protein, the protein that binds the 3 ' end of histone mRNA, is cell cycle regulated by both translational and posttranslational mechanisms. Mol. Cell. Biol 2000;20:4188-4198.4198 [PubMed: 10825184] This paper shows that SLBP is cell-cycle-regulated in mammals and accumulates only in S phase cells. 
a

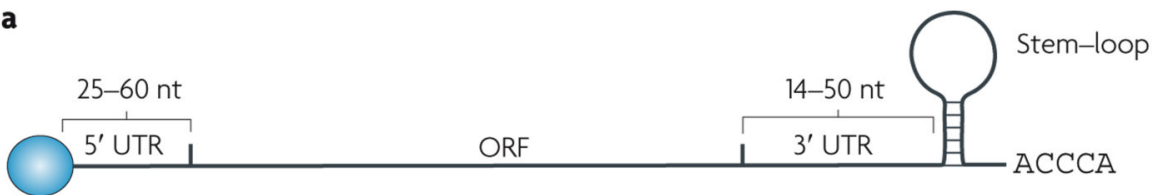

b

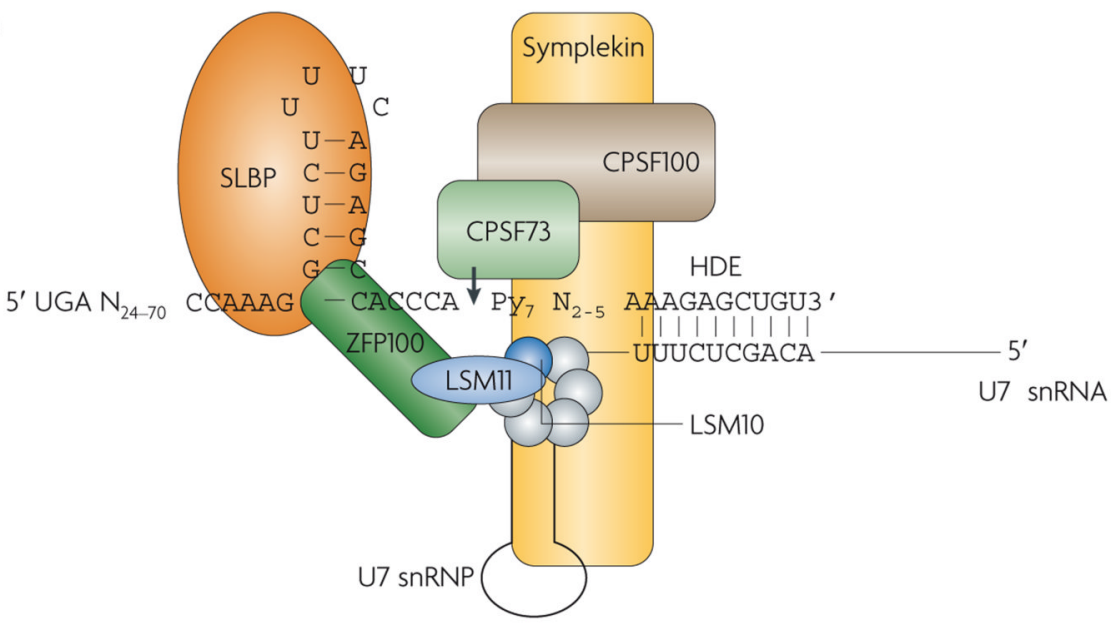

c

U

U

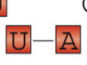

$\mathrm{C}-\mathrm{G}$

$\mathrm{U}-\mathrm{A}$

$C-G$

$\mathrm{G}-\mathrm{C}$

CCAAAG - CACCCA

Homo sapiens

U U

U

U- $\mathrm{A}$

$\mathrm{U}-\mathrm{A}$

$\mathrm{G}-\mathrm{C}$

$\mathrm{U}-\mathrm{A}$

G-C

CCAAAG - CACACA

Dictyostelium

discoideum

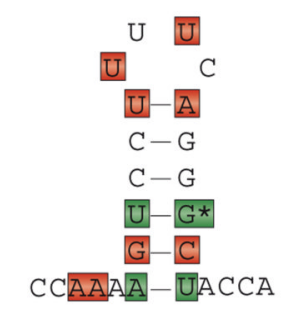

Drosophila melanogaster

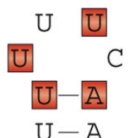

$\mathrm{U}-\mathrm{A}$

$A-U$

G-C

UAAUUG - CACCUG

Trichomonas

vaginalis

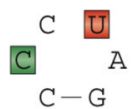

$\mathrm{C}-\mathrm{G}$

$\mathrm{U}-\mathrm{A}$

$\mathrm{U}-\mathrm{A}$

$\mathrm{C}-\mathrm{G}$

G-C

UUUGAG - CAUUAC

Plasmodium berghei

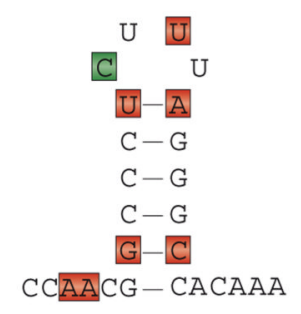

Caenorhabditis elegans

U U

A

$\mathrm{U}-\mathrm{A}$

$\mathrm{A}-\mathrm{U}$

$\mathrm{U}$ C*

G-C

G-C

GUUA]CA- UACUAA

Tetrahymena thermophila

Figure 1. Structure and formation of canonical histone mRNAs

a The structure of a metazoan canonical histone mRNA. There are no introns in these genes, and the mRNAs have short 5' and 3' UTRs. The distance from the stop codon to the start of the conserved 26 nucleotide (nt) sequence at the $3^{\prime}$ end of the mRNA is 25-60 nucleotides and this distance is crucial for regulation of histone mRNA stability. b Processing of mammalian canonical histone pre-mRNA. These pre-mRNAs contain the conserved stem-loop sequence that binds stem-loop binding protein (SLBP) followed by the histone downstream element (HDE), which base-pairs with U7 small nuclear RNA (snRNA). A cleavage complex containing CPSF73 (cleavage and polyadenylation specificity factor subunit 73), CPSF100, symplekin, and possibly FIP1 as well as some unknown factors (not shown) is recruited to 
cleave the pre-mRNA. Within this complex, CPSF73 is the endonuclease that performs the cleavage (arrow), which occurs five nucleotides downstream of the stem-loop and upstream of the HDE. The U7 snRNA is a component of the U7 small nuclear ribonucleoprotein (snRNP), which contains a heptameric ring of five Sm proteins (blue circles) and two U7 snRNP-specific Sm-like proteins, LSM11 and LSM10 (blue ovals). LSM11 contacts a $100 \mathrm{kDa}$ zinc finger protein (ZFP100), which also interacts with the SLBP-stem-loop complex. c The stem-loop structure of the three histone mRNAs from metazoans that show the greatest divergence (top), and from four protozoans ${ }^{99}$ (bottom), showing the limited range of sequence divergence.

Nucleotide positions identified as crucial for SLBP binding 5,100 in mammals are shown in red. Deviations from the consensus stem-loop are in green. Asterisks indicate lack of WatsonCrick base-pairing. 


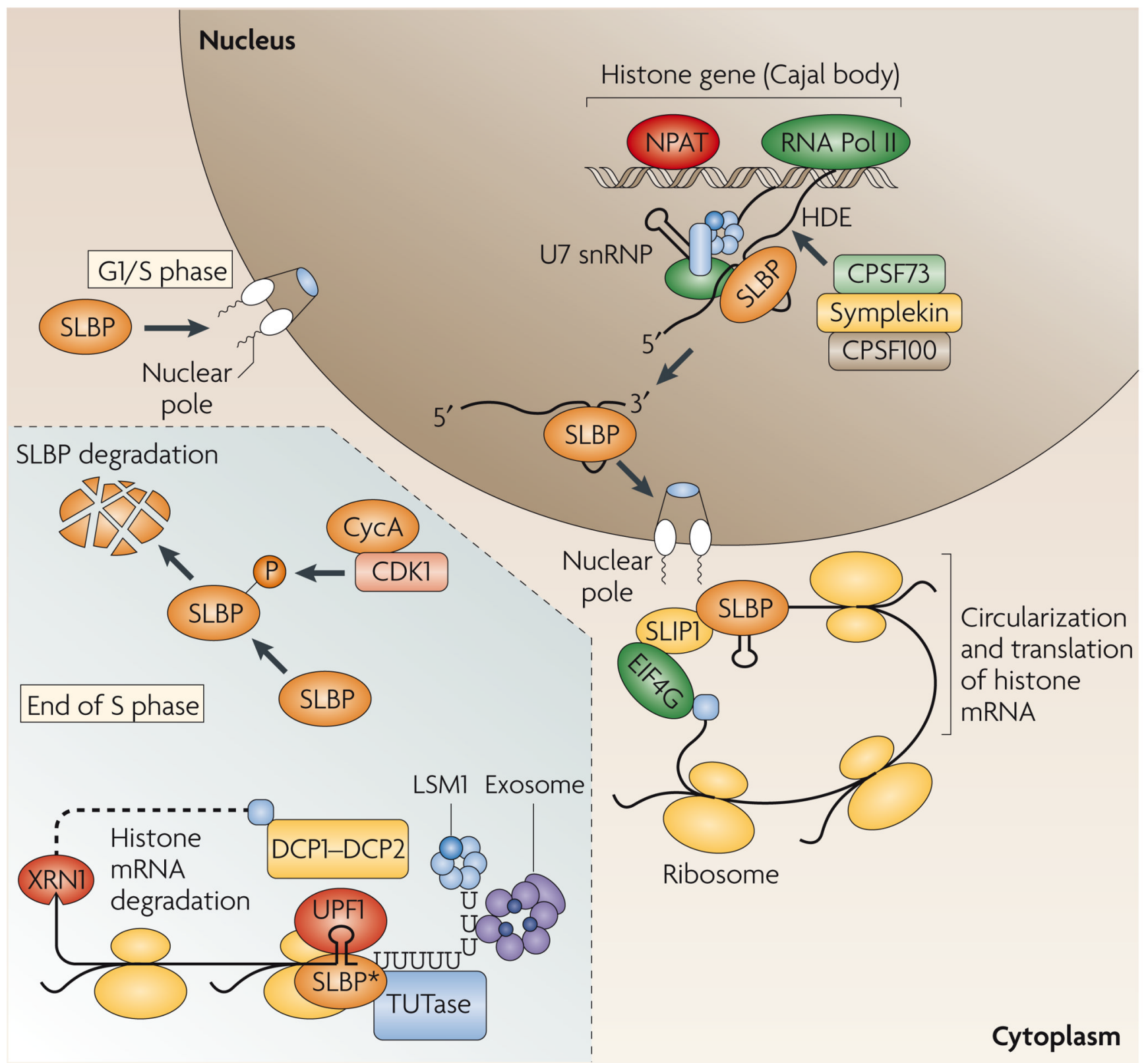

Figure 2. Global view of histone mRNA metabolism in mammalian cells

Transcription of the canonical histone genes and processing of the resulting pre -mRNA occur close to a Cajal body. The U7 small nuclear ribonucleoprotein (snRNP), stem-loop binding protein (SLBP), and the cleavage complex are responsible for the cleavage of the pre-mRNA from the DNA template, forming the mature histone mRNA. SLBP remains bound to the histone mRNA as it goes to the cytoplasm, where histone mRNA is circularized through a complex of proteins including at least SLBP, SLBP-interacting protein 1 (SLIP1) and eukaryotic translation initiation factor 4- $\gamma$ (EIF4G) mediating translation of histone mRNA. At the end of $\mathrm{S}$ phase, a short $\mathrm{U}$ tail is added to histone mRNA in the cytoplasm. The LSM17 ring binds the oligo(U) to cooperate in the recruitment of the decapping complex and the exosome to degrade the mRNA in both the $5^{\prime}$ to $3^{\prime}$ and $3^{\prime}$ to $5^{\prime}$ direction. In addition, cyclin A (CycA)-CDK1 (cyclin-dependent kinase 1) phosphorylates SLBP to trigger its degradation at 
the end of S phase, preventing further histone mRNA synthesis. CPSF, cleavage and polyadenylation specificity factor; DCP, mRNA decapping enzyme; HDE, histone downstream element; LSM, Sm-like protein; NPAT, nuclear protein, ataxia-telangiectasia locus; Pol, polymerase; TUTase, terminal uridylyltransferase; XRN1, 5'-3' exoribonuclease 1. 


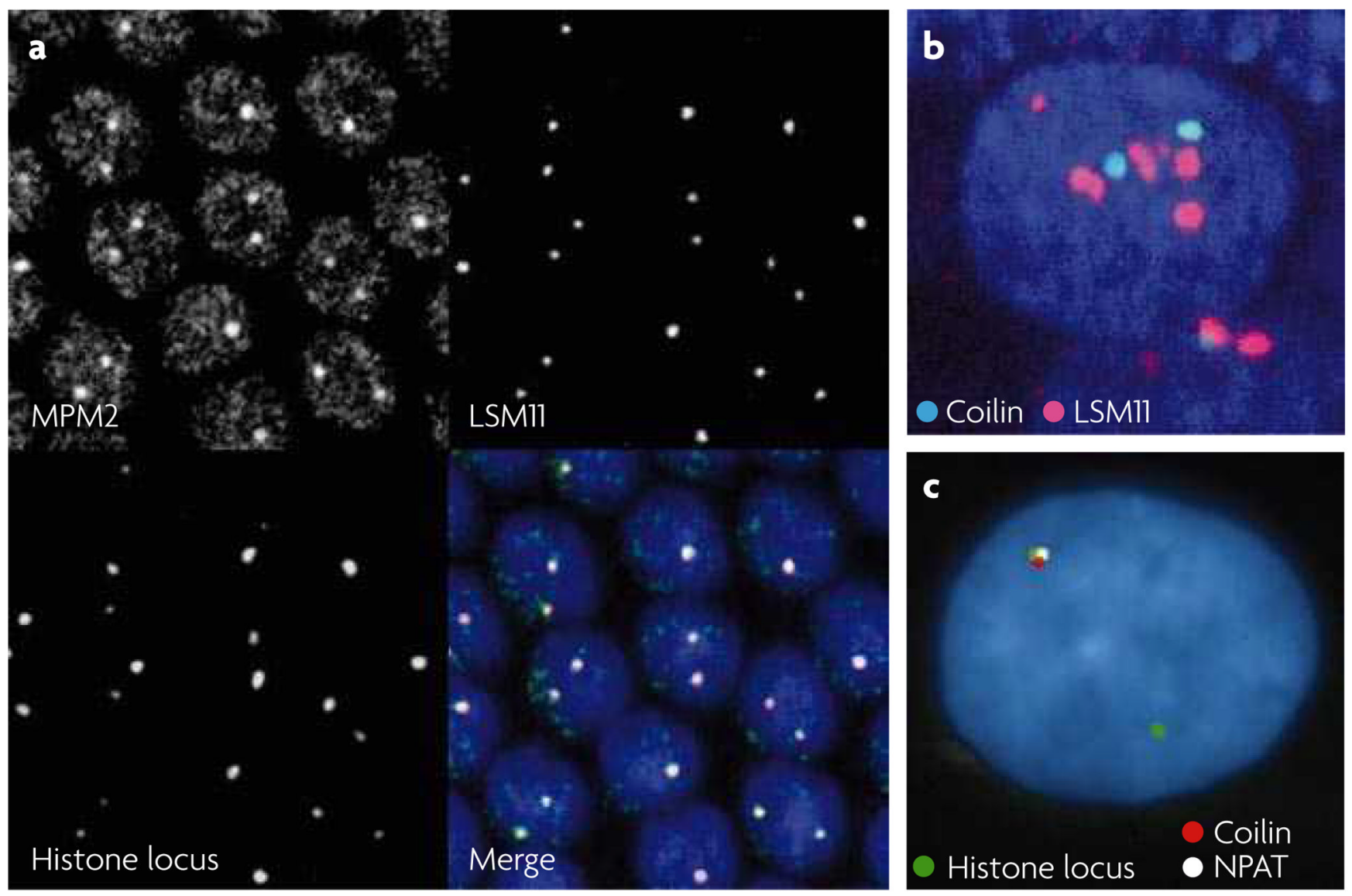

Figure 3. The Cajal body and the histone locus body (HLB)

a HLB in Drosophila melanogaster embryonic blastoderm nuclei. LSM11 and MPM2 colocalize with the histone locus (detected by fluorescence in situ hybridization). Note that these diploid cells have either one or two HLBs, depending on whether homologous chromosomes are paired. Images reproduced, with permission, from REF. ${ }^{41}$ C) 2007 The American Society for Cell Biology. b HLB (LSM11) and Cajal bodies (coilin) are distinct in D. melanogaster ovarian nurse cells. Note the multiple HLB in these highly polyploid cells. Image provided by Joe Gall, Carnegie Institute, Baltimore, USA. c NPAT and coilin localize to histone genes in a human HeLa cell. Image provided by Greg Matera, The University of North Carolina at Chapel Hill, USA. 


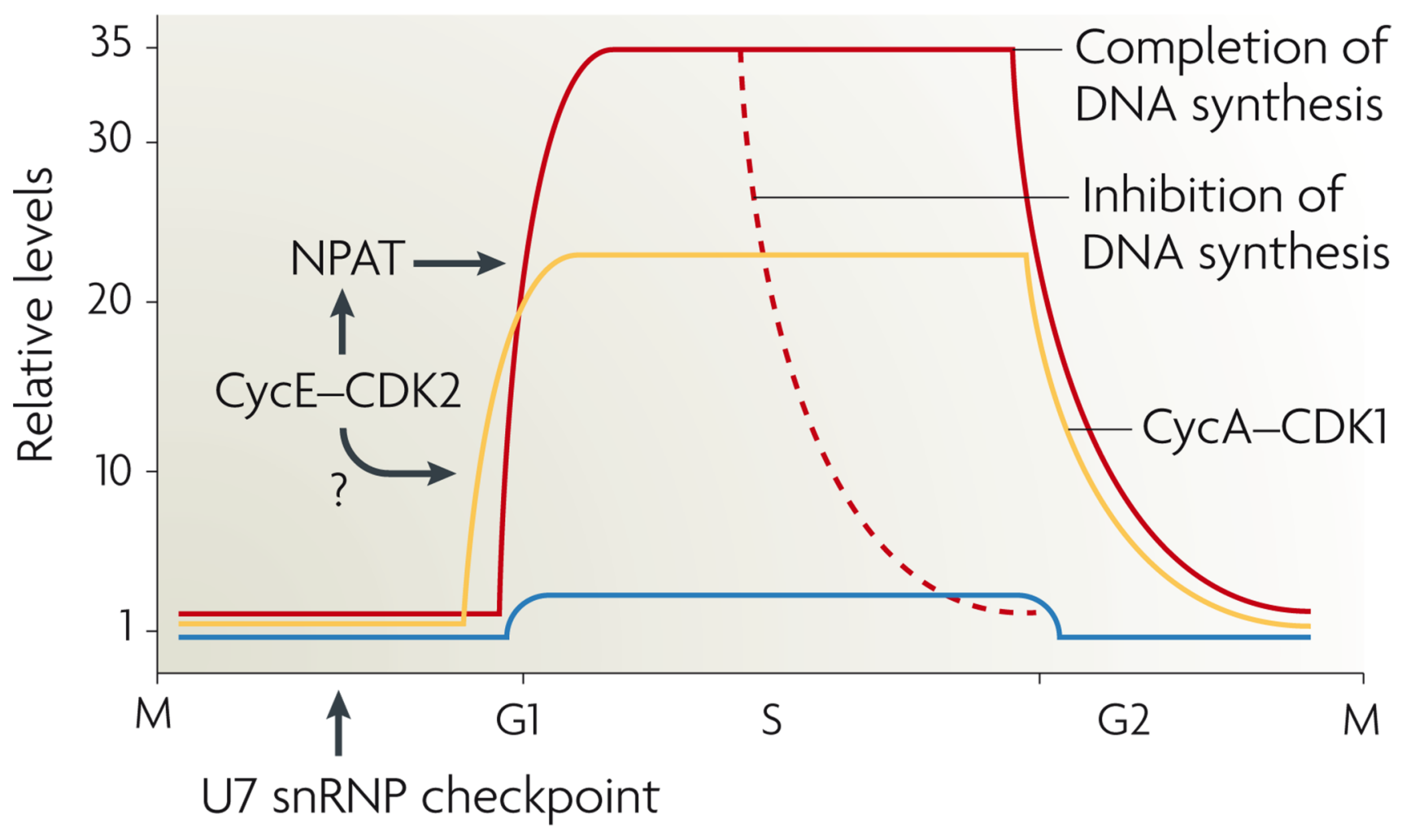

Histone mRNA

Figure 4. Cell-cycle regulation of canonical hist one mRNA

The levels of canonical histone mRNA, SLBP protein and SLBP mRNA during the mammalian cell cycle are shown. Synchronous Chinese hamster ovary (CHO) cells selected by mitotic shake-off were used for measurement of histone mRNA levels by S1 nuclease protection ${ }^{58}$. Histone mRNA degradation and SLBP degradation were measured in detail in HeLa cells synchronized by double thymidine block ${ }^{65,101}$. Essentially identical results have been observed in CHO, HeLa and U2OS cells synchronized by mitotic shake-off, nocodazole block or double thymidine block. During G1 there are low levels of both SLBP and histone mRNA.

Accumulation of histone mRNA requires activation of cyclin E (cycE)-CDK2 (cyclindependent kinase 2) and phosphorylation of nuclear protein, ataxia-telangiectasia locus (NPAT). Histone mRNAs then increase rapidly as cells enter S phase. Completion of DNA synthesis at the end of $\mathrm{S}$ phase, or the inhibition of DNA replication owing to DNA damage, results in a rapid reduction in the levels of histone mRNA. SLBP protein levels also increase rapidly as cells approach $\mathrm{S}$ phase, and are reduced by activation of cycA-CDK1 activity at the conclusion of $S$ phase but not by inhibiting DNA replication during $S$ phase. A defect in active U7 small nuclear ribonucleoprotein (snRNP) results in an arrest in G1, suggesting the existence of a 'histone checkpoint' in G1. By contrast, replication-independent histone H3.3 mRNA levels are constant ${ }^{58}$ and SLBP mRNA levels only vary slightly during the cell cycle. 


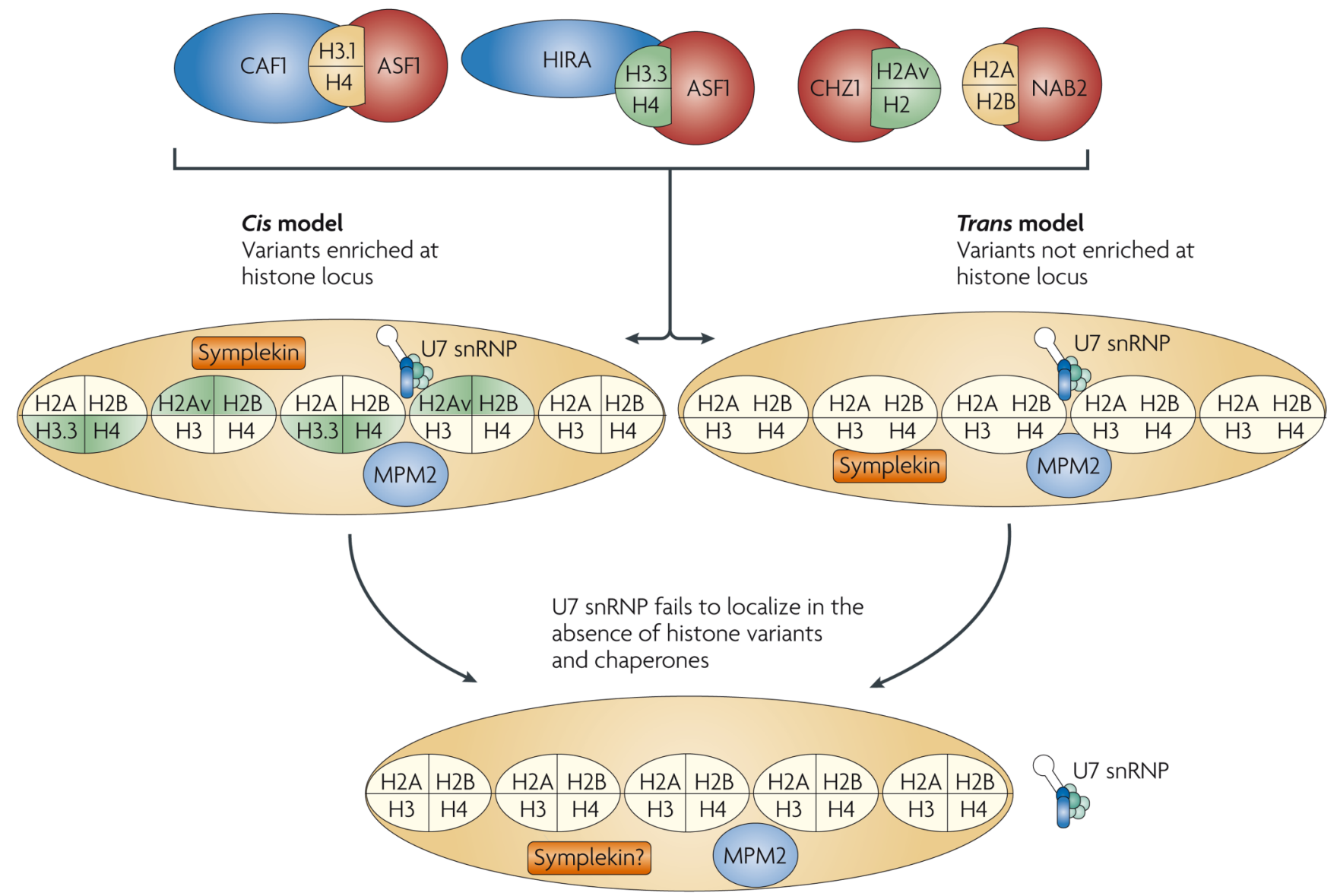

Figure 5. Two models for histone variant function in core histone mRNA 3 ' end formation The two sets of histone chaperones, for canonical histones (CAF1 for H3.1 and NAB2 for histone H2A.1) and for replacement variant histones (HIRA for H3.3 and CHZ1 for H2Av), are shown. In the cis model of histone variant function in $3^{\prime}$ end formation, the histone variants are enriched in histone gene chromatin. The presence of the histone variants is necessary for the recruitment of the histone pre-mRNA processing machinery and incorporation of U7 small nuclear ribonucleoprotein (snRNP) into the histone locus body. In the trans model of histone variant function, the lack of sufficient histone variant proteins assembled into bulk chromatin results in the generation of an unknown signal that results in failure to maintain a fully formed histone locus body. One possibility is that ASF1, present in multiple chromatin assembly complexes, has a direct role in the signalling process. 

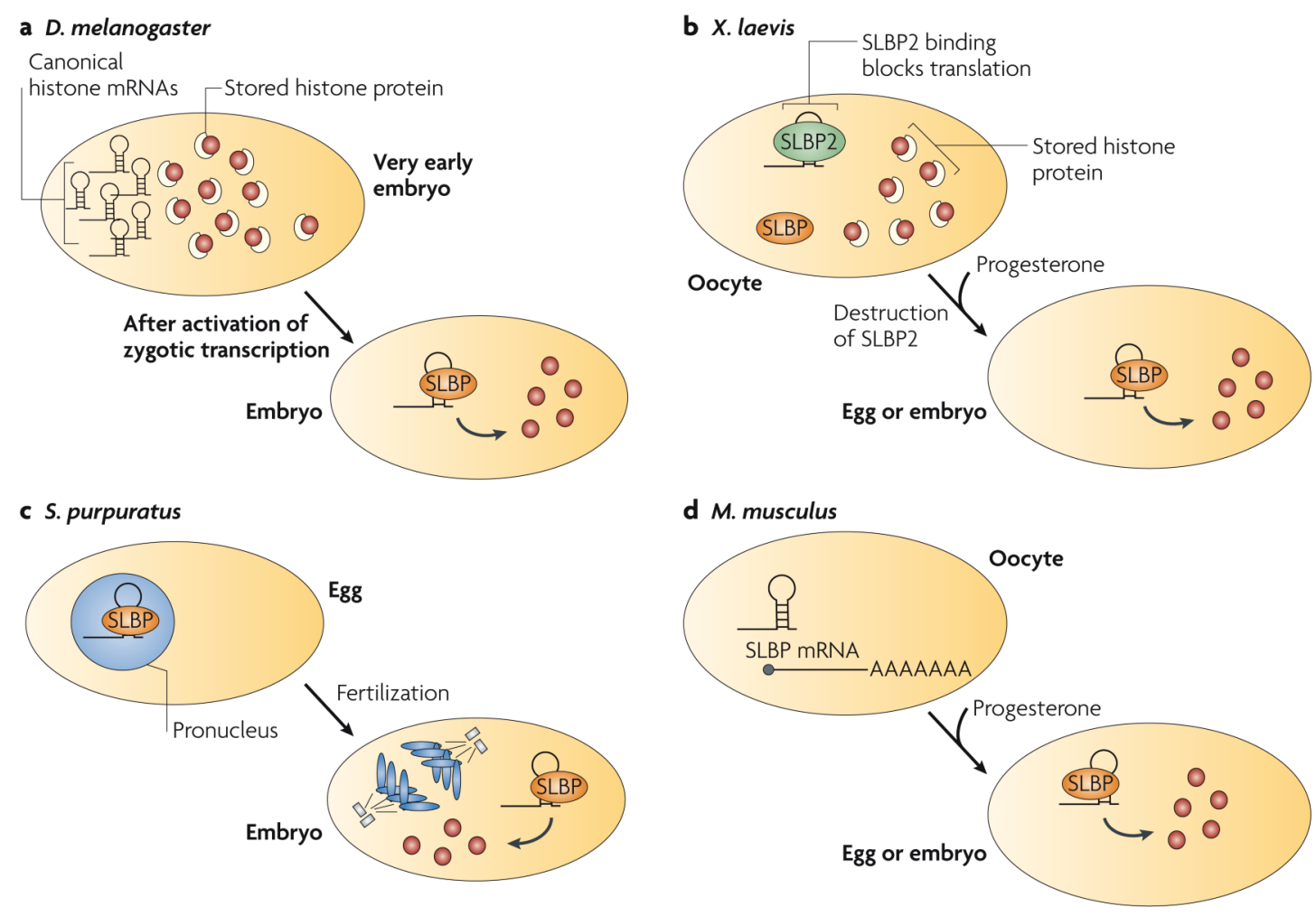

Figure 6. Strategies for supplying canonical histones in early embryogenesis a In Drosophila melanogaster, histone mRNA is synthesized at the end of oogenesis, translated, and histone protein and mRNA is loaded into the oocyte from the nurse cells. In the early embryo, stem-loop binding protein (SLBP) is not active and no histone mRNA is transcribed, and the stored histone protein provides the supply of histone until histone gene transcription is activated. b In Xenopus laevis, histone mRNA is made early in oogenesis and translated to provide a store of histone protein. Histone mRNA made later in oogenesis is stored in association with a distinct SLBP, SLBP2, which represses histone mRNA translation. SLBP2 is destroyed during oocyte maturation and SLBP1 can then bind, activating translation of the stored histone mRNA. The combination of stored histone protein, synthesized early in oogenesis, and newly synthesized histone protein provides the histones until zygotic transcription is activated. $\mathbf{c}$ In the sea urchin Strongylocentrus purpuratus, histone mRNA is synthesized and retained in the pronucleus after completion of meiosis, where it is probably complexed with SLBP. The histone messenger ribonucleoprotein (mRNP) is released after the first mitosis, allowing translation of histone mRNA in the next cell cycle. $\mathbf{d}$ In the mouse, histone mRNA and SLBP mRNA are synthesized in the oocyte but SLBP protein does not accumulate. During oocyte maturation, SLBP rapidly accumulates owing to translation of the maternal mRNA. This SLBP can then activate the translation of maternal histone mRNA. 
Table 1

Factors involved in canonical histone mRNA metabolism

\begin{tabular}{lll}
\hline Process & Unique to canonical histone mRNAs & Common with polyadenylated mRNAs \\
\hline Transcription & NPAT, FLASH & HINFD, OCT1, OCA-S, YY1 \\
Processing & SLBP, U7 snRNP (U7 snRNA, LSM11- & Symplekin, CPSF100, CPSF73, FIP1 \\
& LSM10), ZFP100 & \\
Translation & SLBP, SLIP1 & EIF4GI, EIF4GII \\
Decay & SLBP, TUTase & LSM1, exosome, UPF1, decapping, XRN1 \\
\hline
\end{tabular}

All of the factors listed are present in mammals and all except zinc finger protein 100 (ZFP100) probably have orthologues in Drosophila melanogaster. Some factors, terminal uridylyltransferase (TUTase) and SLBP-interacting protein 1 (SLIP1), may have functions other than in histone mRNA metabolism. CPSF, cleavage and polyadenylation specificity factor; EIF4G, eukaryotic translation initiation factor 4- $\gamma$; FLASH, FLICE-associated huge protein; HINFD, histone promoter-associated nuclear factor 1; LSM, Sm-like protein; NPAT, nuclear protein, ataxia-telangiectasia locus; OCA-S, OCT1 coactivator in S phase; OCT1, octamer-binding transcription factor 1; SLBP, stem-loop binding protein; snRNA, small nuclear RNA; snRNP, small nuclear ribonucleoprotein; UPF1, UP frameshift 1; XRN1, 5'-3' exoribonuclease 1; YY1, YY1 transcription factor. 